\title{
SISTEM PENDUKUNG KEPUTUSAN PEMILIHAN SISWA BERPRESTASI; METODE PROFILE MATCHING
}

\author{
Zulfahmi $^{1)}$, Faradika $^{2)}$. \\ ${ }^{1}$ Program Studi Sistem Informasi, Universitas Dharma Andalas \\ email : zulfahmi@unidha.ac.id \\ 2 Program Studi Sistem Informasi, Universitas Dharma Andalas \\ email: faradika@unidha.ac.id
}

\begin{abstract}
This research was conducted to assist the school in terms of selection of creative students, especially those using Kurikulum 2013 or better known as K-13. We conclude that the subjective application of student achievement with the 2006 curriculum is more commonly referred to as Kurikulum Tingkat Satuan Pendidikan (KTSP) has been widely circulated schools. The limits given in the decision support system of selecting student achievement include the determination of criteria and using Profile Matching method which leads to the determination of GAP value, the smaller the gap value the greater the chance to be selected as a student achievement. In designing applications researchers use using tools such as UML (Unified Modeling Language) in order to make it easier to move the concept of a system designed into the form of the program.
\end{abstract}

Keywords: The Curriculum 2013,UML, Profile Matching method , KTSP

\section{PENDAhuluan}

Setiap individu siswa memiliki hard skills dan soft skills yang berpotensi dalam menunjang masa depannya. Namun, tidak semua individu tersebut memiliki kemauan dan kemampuan dalam mengekplorasi potensi yang dimilikinya.

Proses pemilihan siswa berprestasi yang dilakukan selama ini oleh pihak sekolah masih memiliki beberapa kelemahan sehingga menimbulkan beberapa persoalan, diantaranya proses pengolahan data pemilihan siswa berprestasi yang memakan waktu lama serta kemungkinan terjadinya human error dalam proses pengolahan data.

Dukungan komputerisasi dalam hal pengambilan keputusan telah masuk ke segala bidang. Salah satunya adalah Sistem Pendukung Keputusan pemilihan siswa berprestasi yang berbasis komputer. Didalam proses pemilihan siswa berprestasi yang melibatkan banyak komponen atau kriteria yang dinilai (multicriteria), diperlukan sebuah sistem pendukung keputusan yang berbasis komputer sehingga dapat membantu dalam menentukan alternatif pemilihan siswa berprestasi.

Salah satu komponen atau kriteria yang dinilai adalah aspek pengetahuan yang akan diambil dari sistem penilaian dalam proses belajar mengajar di kelas. Ada 2 kurikulum yang diterapkan oleh pihak sekolah, yaitu : Kurikulum 2006 lebih sering disebut dengan Kurikulum Tingkat Satuan Pendidikan (KTSP) dan Kurikulum 2013 (K-13). Masingmasing kurikulum ini memiliki kekurangan dan kelebihan, disini peneliti memutuskan untuk menggunakan K-13 dimana secara subyektif peniliti sedikit lebih kompleks sehingga lebih menantang penilti.

Salah satu metode sistem pendukung keputusan adalah Metode Profile Matching. Dalam proses profile matching secara garis besar merupakan proses membandingkan antara kompetensi siswa sehingga dapat diketahui perbedaan kompetensinya (disebut juga GAP), semakin kecil gap yang dihasilkan maka bobot nilainya semakin besar yang berarti memiliki peluang lebih besar untuk siswa masuk sebagai siswa berpretasi. Oleh karena itu metode ini cukup efektif 
dalam menyederhanakan dan mempercepat proses pengambilan keputusan dengan memecahkan persoalan tersebut ke dalam bagian-bagiannya

\section{KAJIAN LITERATUR}

Decision Support System (DSS) merupakan sistem informasi interaktif yang menyediakan informasi, pemodelan dan pemanipulasian data. Sistem itu digunakan untuk membantu pengambilan keputusan dalam situasi yang semiterstruktur dan situasi yang tidak terstruktur, di mana tak seorang pun tahu secara pasti bagaimana keputusan seharusnya dibuat.

Menurut Kusrini (2007:25) Suatu sistem pendukung keputusan memiliki tiga subsistem utama yang menentukan kapabilitas teknis sistem pendukung keputusan tersebut, yaitu :

\section{Subsistem Manajemen Basis Data}

Sistem pendukung keputusan membutuhkan proses ekstraksi dan Data Base Management Subsystem (DBMS) yang dalam pengelolaannya harus cukup fleksibel untuk memungkinkan penambahan dan pengurangan secara cepat.

\section{Subsistem Manajemen Basis Model}

Salah satu keunggulan dalam sistem pendukung keputusan adalah kemampuan untuk mengintegrasikan akses data dan model-model keputusan.

\section{Subsistem Perangkat Lunak Penyelenggara Dialog}

Fleksibilitas dan kekuatan karakteristaik sistem pendukung keputusan timbul dari kemampuan interaksi antara sistem dan pemakai, yang dinamakan subsistem dialog. Bennet mendefinisikan pemakai, terminal dan sistem perangkat lunak sebagai komponenkomponen dari sistem dialog

\section{Metoda Profile Matching}

Menurut Kusrini (2007:53) metode profile matching atau pencocokan profil adalah metode yang sering digunakan sebagai mekanisme dalam pengambilan keputusan dengan mengasumsikan bahwa terdapat tingkat variabel prediktor yang ideal yang harus dipenuhi oleh subyek yang diteliti, bukannya tingkat minimal yang harus dipenuhi atau dilewati.

Berikut adalah beberapa tahapan dan perumusan perhitungan dengan metode profile matching :

\section{Pembobotan}

Pada tahap ini, akan ditentukan bobot nilai masing-masing aspek dengan menggunakan bobot nilai yang telah ditentukan bagi masing-masing aspek itu sendiri. Adapun inputan dari proses pembobotan ini adalah selisih dari profil karyawan dan profil jabatan.

\section{Pengelompokan Core Factor dan Secondary Factor}

Setelah menentukan bobot nilai gap kriteria yang dibutuhkan, kemudian tiap kriteria dikelompokan lagi menjadi dua kelompok yaitu core factor dan secondary factor.

\section{Perhitungan}

Nilai Total Dari perhitungan core factor dan secondary factor dari tiap-tiap aspek, kemudian dihitung nilai total dari tiap-tiap aspek yang diperkirakan berpengaruh pada kinerja tiap-tiap profile. Untuk menghitung nila total dari masing- masing aspek, digunakan rumus :

Keterangan :

$$
\mathrm{N}=(\mathrm{X}) \% \mathrm{NCI}+(\mathrm{X}) \% \mathrm{NSI}
$$

$$
\begin{array}{ll}
\mathrm{N} & =\text { Nilai Total Tiap Aspek } \\
\mathrm{NCI} & =\text { Nilai Core Factor } \\
\mathrm{NSI} & =\text { Nilai Secondary Factor }
\end{array}
$$

$(\mathrm{X}) \%=$ Nilai Persentase .

\section{Perangkingan}

Hasil akhir dari proses profile matching adalah rangking dari kandidat yang diajukan untuk mengisi suatu jabatan/posisi tertentu. Penentuan mengacu rangking pada hasil perhitungan yang ditujukan pada rumus dibawah ini :

Rangking $=20 \% \mathrm{NKI}+30 \% \mathrm{NSK}+50 \% \mathrm{NP}$

Keterangan :

NKI = Nilai Kapasitas Intelektual

NSK = Nilai Sikap Kerja

$\mathrm{NP}=$ Nilai Perilaku

\section{METODE PENELITIAN}

Metodologi untuk Pengembangan System merupakanproses standard yang digunakan team pengembang untuk menghubungkan 
semua langkah yang diperlukan untuk menganalisa, merancang, mengimplementasi, dan memelihara SI. Adapun metodologi yang sampai saat ini masih sesuai untuk menjadi pedoman dalam pengembangan sistem adalah SDLC. System Development Life Cycle (SDLC) adalah metodologi yang digunakan untuk mengembangkan, memelihara, dan/atau mengganti SI.

Gambar 3.1 berikut adalah bagan dari SDLC yang umum dimana terdiri atas 7 phase. Sesuai gambar sehigga SDLC juga sering disebut metodologi 'Waterfall ' karena lebih menyerupai air terjun

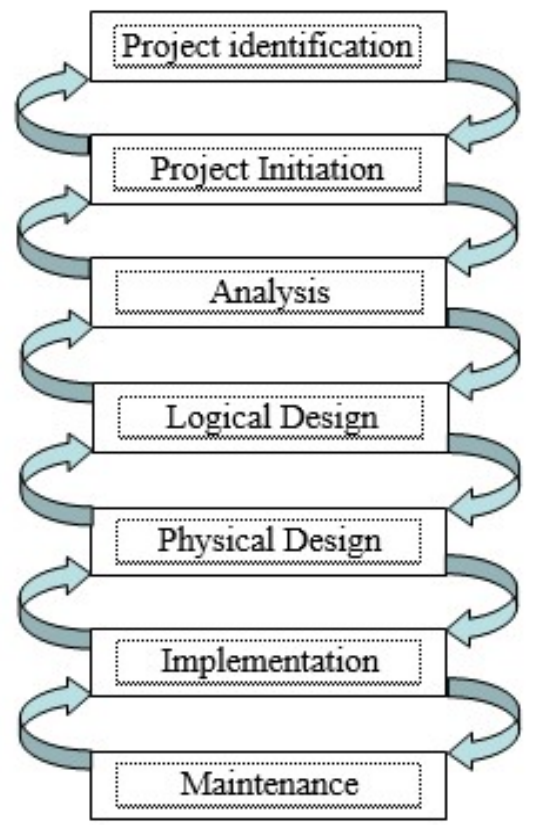

Gambar.1 SDLC dengan 7 phase

Output atau produk yang dihasilkan ditiap phase SDLC

\section{Project Identification \& Selection, menghasilkan :}

Perencanaan Sistem, yaitu menentukan prioritas sistem dan proyek, arsitektur dari data, jaringan, hardware, dan manajemen dari sistem informasi. Pada tahap ini akan dilakukan indentifikasi terhadap permasalahan yang ada sehubungan dengan tujuan pembangunan perancangan aplikasi. Untuk kegiatan ini diperlukan waktu 1 bulan.

$$
\begin{aligned}
& \text { Project Initiation \& Planning, } \\
& \text { menghasilkan : }
\end{aligned}
$$

Langkah terperinci atau rencana kerja untuk proyek, spesifikasi dari ruang lingkup penelitian dan syarat/bentuk sistem (highlevel), tugas untuk anggota team dan sumber daya lainnya, sistem perundangan /pertimbangan. Dalam tahap ini dilakukan akan ditentukan ruang lingkup dan batasan penelitian, perencanaan sistem serta rencana pengalokasian sumber daya yang dimiliki untuk melaksanakan penelitian ini. Kegiatan ini akan memakan waktu sekitar 2 bulan dan direncanakan akan dimulai di bulan ke dua penelitian ini.

\section{Analysis, menghasilkan :}

Kegiatan yang diprediksi akan memakan waktu kurang lebih 8 bulan ini bertujuan melakukan penjabaran mengenai sistem yang ada termasuk masalah atau peluang yang ada yang direkomendasi untuk di perbaiki/ diatasi, ditingkatkan, atau mengganti sistem yang ada, uraian mengenai sistem pilihan dan sistem perundangan /pertimbangan untuk sistem yang terpilih. Di sini akan dilakukan studi evaluasi terhadap sistem yang sedang berjalan saat ini sehubungan dengan upaya yang telah dilakukan untuk perancangan aplikasi sistem pendukung keputusan pemilihan siswa berprestasi; metode profile matching. Melalui kegiatan analisis ini akan dihasilkan rekomendasi perbaikan demi tercapainya tujuan penelitian.

\section{Logical Design, menghasilkan :}

Berhubungan dengan fungsi-fungsi, spesifikasi terperinci dari semua element sistem (data, proses, input, output). Pada tahap ini akan dilakukan perancangan terhadap fungsi-fungsi logic dari perancangan aplikasi sistem pendukung keputusan pemilihan siswa berprestasi; metode profile matching. Perancangan logic ini rencananya akan memakan waktu sekitar 1 bulan.

\section{Physical design, menghasilkan :}

Tahapan ini lebih bersifat teknis, spesifikasi terperinci dari semua element sistem (program, file-file, jaringan, sistem software, dll), rencana untuk teknologi baru. Tahap ini akan memberikan hasil berupa rancangan fisik berupa jenis software yang akan digunakan, tools yang akan digunakan untuk implementasi sistem serta spesifikasi 
hardware yang dibutuhkan. Sehingga sistem yang diinginkan bisa direalisasikan. Pelaksanaannya diprediksi sekitar 2 bulan.

Implementation, menghasilkan :

Code /listing program, dokumentasi, prosedur pelatihan, dan support /dukungan yang dapat diberikan. Tahap ini akan memberikan output berupa sistem yang diinginkan yaitu sebuah sistem sistem pendukung keputusan pemilihan siswa berprestasi; metode profile matching yang mampu membantu dalam memberikan informasi yang tepat dan akurat dan akan memakan waktu kurang lebih 2 bulan.

\section{Maintenance, menghasilkan :}

Software versi terbaru atau dengan pembaruan untuk dokumentasi, pelatihan, support/dukungan terhadap hasil penelitian.

\section{HASIL DAN PEMBAHASAN}

\section{Batasan Dalam Sistem Perangkat Lunak}

Batasan yang diberikan dalam sistem pendukung keputusan pemilihan siswa berprestasi diantaranya adalah sebagai berikut

- Bagian aspek dan kriteria penilaian yang digunakan dalam sistem sengaja dibuat secara dinamis dengan tujuan agar pada saat kedepannya apabila ada perubahan terhadap sistem, maka tidak akan susah dengan membongkar program dan databasenya. Daftar aspek tersebut diantaranya sebagai berikut:

$$
\begin{array}{ll}
\text { A1 } & \text { : Pengetahuan } \\
\text { A2 } & \text { : Ketrampilan } \\
\text { A3 } & \text { : Sikap }
\end{array}
$$

- Alternatif ditentukan dari hasil pendekatan dengan menggunakan metode Profile Matching, penentuan peringkat atau rangking dari kandidat didasarkan pada besaran nilai hasil akhir yang dimilikinya. Sehinga semakin besar nilai hasil akhir yang dimiliki maka semakin besarpula kesempatan bagi kandidat tersebut untuk direkomendasikan oleh sistem ini sebagai siswa berprestasi.

\section{- Analisa Input}

Data masukan (input) yang dibutuhkan oleh sistem untuk mengolah dan merangking setiap alternatif adalah data siswa, data aspek dan kriteria, nilai siswa untuk tiap kriteria, nilai core dan secondary factor, dan nilai presentase dari masing-masing aspek.

\section{- Analisa Output}

Data keluaran (output) dari aplikasi ini adalah menentukan peringkat atau rangking dari kandidat berdasarkan pada besaran nilai hasil akhir yang dimiliki oleh setiap alternatif sehingga semakin besar nilai hasil akhir yang dimiliki, maka semakin besar pula kesempatan bagi siswa tersebut untuk terpilih sebagai siswa berprestasi, begitu pula sebaliknya. Sehingga memudahkan pimpinan dalam menentukan calon siswa berprestasi.

- Analisis Proses Sistem

Pada analisis proses sistem yang akan dibangun, penggunaan metode profile matching membutuhkan inputan profil siswa dan profil pencapaian yang merupakan nilai acuan pada siswa berprestasi. Setelah diperoleh profil pencapaian, kemudian dilakukan pemetaan gap kompetensi yang merupakan selisih dari profil siswa dengan profil pencapaian. Hasil yang didapat dari pemetaan gap akan dilakukan proses pembobotan nilai gap. Kemudian mengelompokan dan menghitung nilai core factor dan secondary factor. Selanjutnya akan dilakukan proses perhitungan nilai total dan rangking siswa dari urutan tertinggi sampai terendah yang layak untuk menjadi siswa berprestasi.

Berikut adalah langkah-langkah proses penyelesaian menggunakan metode profil matching :

\section{Pemetaan Gap Kompetensi}

Gap adalah selisih antara profil siswa dengan profil pencapaian yang ditentukan oleh pihak sekolah. Pengumpulan gapgap pada setiap kriteria mempunyai perhitungan yang berbeda-beda.

Rumus untuk pencarian Gap kompetensi:

Gap $=$ Profil Siswa - Profil Pencapaian

1) Nilai dari tiap aspek dan kriteria yang ditetapkan oleh pihak sekolah dalam pemilihan siswa berprestasi :

\section{a) Kriteria Aspek Pengetahuan dan Keterampilan}




\begin{tabular}{|c|c|}
\hline Agama & Bobot \\
\hline Nilai dari $3.67 \mathrm{~s} / \mathrm{d} 4.00$ & 10 \\
\hline Nilai dari $3.34 \mathrm{~s} / \mathrm{d} 3.66$ & 9 \\
\hline Nilai dari $3.01 \mathrm{~s} / \mathrm{d} 3.33$ & 8 \\
\hline Nilai dari $2.67 \mathrm{~s} / \mathrm{d} 3.00$ & 7 \\
\hline Nilai dari $2.34 \mathrm{~s} / \mathrm{d} 2.66$ & 6 \\
\hline Nilai dari $2.01 \mathrm{~s} / \mathrm{d} 2.33$ & 5 \\
\hline Nilai dari $1.67 \mathrm{~s} / \mathrm{d} 2.00$ & 4 \\
\hline Nilai dari $1.34 \mathrm{~s} / \mathrm{d} 1.66$ & 3 \\
\hline Nilai dari $1.01 \mathrm{~s} / \mathrm{d} 1.33$ & 2 \\
\hline Nilai dari $0 \mathrm{~s} / \mathrm{d} 1.00$ & 1 \\
\hline
\end{tabular}

Tabel. 1 Kriteria Aspek Penegtahuan dan Keterampilan

a) Kriteria Aspek Sikap

\begin{tabular}{|c|c|}
\hline Kesopanan & Bobot \\
\hline Sangat Baik & 9 \\
\hline Baik & 8 \\
\hline Cukup & 7 \\
\hline Buruk & 6 \\
\hline Sangat Buruk & 5 \\
\hline
\end{tabular}

Tabel1 Kriteria Kesopanan dan Prilaku

\section{Profil Pencapaian/Ideal}

Penentuan nilai profil pencapaian akan ditentukan oleh pihak sekolah dengan range nilai antara 1 sampai 10. Dari nilainilai tersebut akan dilakukan proses perhitungan gap antara nilai profil siswa dengan nilai profil pencapaian.Untuk lebih jelasnya berikut adalah nilai pencapaian yang ditetapkan perusahaan di setiap kriteria:

\begin{tabular}{|l|c|c|}
\hline \multicolumn{1}{|c|}{$\begin{array}{c}\text { Aspek } \\
\text { Pengetahuan }\end{array}$} & $\begin{array}{c}\text { Profil } \\
\text { Ideal }\end{array}$ & Jenis \\
\hline $\begin{array}{l}\text { Nilai Agama } \\
\text { (K1) }\end{array}$ & 10 & $\begin{array}{c}\text { Secondary } \\
\text { Factor }\end{array}$ \\
\hline $\begin{array}{l}\text { Nilai } \\
\text { Matematika } \\
\text { (K2) }\end{array}$ & 10 & Core Factor \\
\hline $\begin{array}{l}\text { Nilai Kimia } \\
\text { (K3) }\end{array}$ & 10 & Core Factor \\
\hline $\begin{array}{l}\text { Nilai Fisika } \\
\text { (K4) }\end{array}$ & 10 & Core Factor \\
\hline Nilai Biologi & 10 & Core Factor \\
\hline
\end{tabular}

\begin{tabular}{|l|c|c|}
\hline (K5) & & \\
\hline $\begin{array}{l}\text { Nilai Bahasa } \\
\text { Inggris (K6) }\end{array}$ & 10 & $\begin{array}{c}\text { Secondary } \\
\text { Factor }\end{array}$ \\
\hline $\begin{array}{l}\text { Nilai Bahasa } \\
\text { Indonesia (K7) }\end{array}$ & 10 & $\begin{array}{c}\text { Secondary } \\
\text { Factor }\end{array}$ \\
\hline
\end{tabular}

\section{Tabel2 Nilai Profil Ideal Aspek Pengetahuan}

\begin{tabular}{|c|c|c|}
\hline $\begin{array}{c}\text { Aspek } \\
\text { Pengetahuan }\end{array}$ & $\begin{array}{c}\text { Profil } \\
\text { Ideal }\end{array}$ & Jenis \\
\hline Agama (K11) & 10 & Core Factor \\
\hline $\begin{array}{c}\text { Matematika } \\
\text { (K12) }\end{array}$ & 10 & Core Factor \\
\hline Kimia (K13) & 10 & $\begin{array}{c}\text { Secondary } \\
\text { Factor }\end{array}$ \\
\hline Fisika (K14) & 10 & $\begin{array}{c}\text { Secondary } \\
\text { Factor }\end{array}$ \\
\hline $\begin{array}{c}\text { Biologi (K15) } \\
\text { Bahasa Inggris } \\
\text { (K16) }\end{array}$ & 10 & $\begin{array}{c}\text { Secondary } \\
\text { Factor }\end{array}$ \\
\hline $\begin{array}{c}\text { Bahasa } \\
\text { Indonesia } \\
\text { (K17) }\end{array}$ & 10 & Core Factor \\
\hline
\end{tabular}

Tabel 3 Nilai Profil Ideal Aspek Ketrampilan

\begin{tabular}{|c|c|c|}
\hline Aspek Sikap & $\begin{array}{c}\text { Profil } \\
\text { Ideal }\end{array}$ & Jenis \\
\hline $\begin{array}{c}\text { Kesopanan } \\
\text { (K21) }\end{array}$ & 10 & Core Factor \\
\hline $\begin{array}{c}\text { Tingkah } \\
\text { Laku (K22) }\end{array}$ & 10 & $\begin{array}{c}\text { Secondary } \\
\text { Factor }\end{array}$ \\
\hline
\end{tabular}

Tabel4 Nilai Profil Ideal Aspek Sikap

\section{Perhitungan Penentuan Rangking}

Hasil akhir dari proses Profile Matching adalah rangking dari siswaberprestasi. Pada tahap ini untuk melakukan perhitungan penentuan rangkingmaka nilai total aspek untuk setiap alternatif dikalikan dengan nilai presentaseuntuk tiap-tiap aspek, misalkan pada sistem digunakan nilai presentase aspeksebagai berikut :

1. Pengetahuan $40 \%$

2. Ketrampilan $40 \%$

3.Sikap 20\%

Nilai presentase untuk masingmasing aspek diatas sengaja dibuat dinamis sehingga dapat disesuaikan sewaktu-waktu jika dibutuhkan. Berikut ini adalah 
perhitungan penentuan rangking untuk setiap alternatif.

Rangking $=40 \% \mathrm{NP}+40 \% \mathrm{NK}+20 \% \mathrm{NS}$

1. NISN 9966751650

Ranking $=(40 \% * 7.716)+(40 \% *$ $8.4)+(20 \% * 8)$

$$
=3.086+3.36+1.6
$$

$$
=8.046
$$

2. NISN 9987510956

Ranking $=(40 \% * 7.3)+(40 \% *$ $7.95)+(20 \% * 8.4)$

$$
=2.92+3.18+1.68
$$

$$
=7.78
$$

3. NISN 9996432147

Ranking $=(40 \% * 7.716)+(40 \% *$ $8.25)+(20 \% * 8)$

$$
\begin{aligned}
& =3.086+3.3+1.6 \\
& =7.986
\end{aligned}
$$

\section{NISN 9982884219}

Ranking $=(40 \% * 7.583)+(40 \% *$

$8.55)+(20 \% * 8.6)$

$$
=3.033+3.42+1.72
$$

$$
=8.173
$$

5. NISN 9994250244

Ranking $=(40 \% * 7.716)+(40 \% *$ $8.55)+(20 \% * 8)$

$$
\begin{aligned}
& =3.086+3.42+1.6 \\
& =8.106
\end{aligned}
$$

6. NISN 9997859210

Ranking $=(40 \% * 8)+(40 \% *$

$8.4)+(20 \% * 8.4)$

$=3.2+3.36+1.68$

$$
=8.24
$$

7. NISN 9993953988

Ranking $=(40 \% * 7.583)+(40 \% *$

$7.533)+(20 \% * 8.6)$

$$
\begin{aligned}
& =3.033+3.013+1.72 \\
& =7.766
\end{aligned}
$$

8. NISN 9986517538

Ranking $=(40 \% * 8.883)+(40 \% *$

$8.85)+(20 \% * 9)$

$$
=3.553+3.54+1.8
$$

$$
=8.893
$$

9. NISN 9996710675

Ranking $=(40 \% * 7.566)+(40 \% *$

$7.95)+(20 \% * 9)$

$$
\begin{aligned}
& =3.026+3.18+1.8 \\
& =8.006
\end{aligned}
$$

10. NISN 9995727429

Ranking $=(40 \% * 8.133)+(40 \% *$ $8.25)+(20 \% * 9)$

$$
\begin{aligned}
& =3.253+3.3+1.8 \\
& =8.353
\end{aligned}
$$

Dari hasil perhitungan nilai rangking diatas, maka selanjutnya nilai rangkingdari setiap alternatif di urutkan dari yang terbesar sampai dengan yang terkecil.Sehingga diperoleh urutan rangking dari sistem pendukung keputusan pemilihansiswa berprestasi ini seperti pada tabel 6

\begin{tabular}{|c|c|c|}
\hline No & NISN & $\begin{array}{c}\text { Hasil Akhir } \\
\text { (Ranking) }\end{array}$ \\
\hline $\mathbf{1}$ & 9986517538 & 8.893 \\
\hline $\mathbf{2}$ & 9995727429 & 8.353 \\
\hline $\mathbf{3}$ & 9997859210 & 8.24 \\
\hline $\mathbf{4}$ & 9982884219 & 8.173 \\
\hline $\mathbf{5}$ & 9994250244 & 8.106 \\
\hline $\mathbf{6}$ & 9966751650 & 8.046 \\
\hline $\mathbf{7}$ & 9996710675 & 8.006 \\
\hline $\mathbf{8}$ & 9996432147 & 7.986 \\
\hline $\mathbf{9}$ & 9987510956 & 7.78 \\
\hline $\mathbf{1 0}$ & 9993953988 & 7.766 \\
\hline
\end{tabular}

Tabel 6 Hasil Akhir Proses Profile

Matching

\section{Perancangan}

Perancangan aplikasi sistem pendukung keputusanmenggunakan alat bantu berupa UML (Unified Modelling Language) agar mempermudah memindahkan konsep sistem yang dirancang ke dalam bentuk program, dimana perancangannya digambarkan dalam bentuk diagram-diagram berikut:

\section{Perancangan Aplikasi Menggunakan Use CaseDiagram}

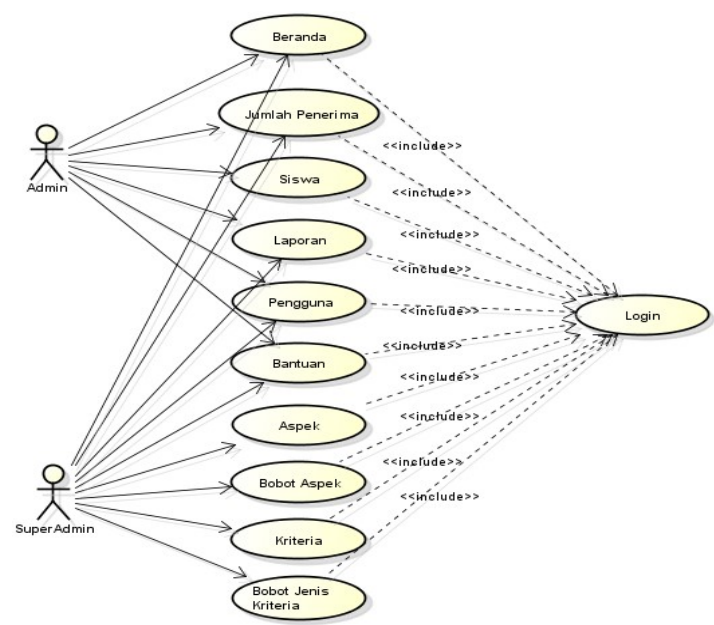

Gambar 2 Use Case Diagram 


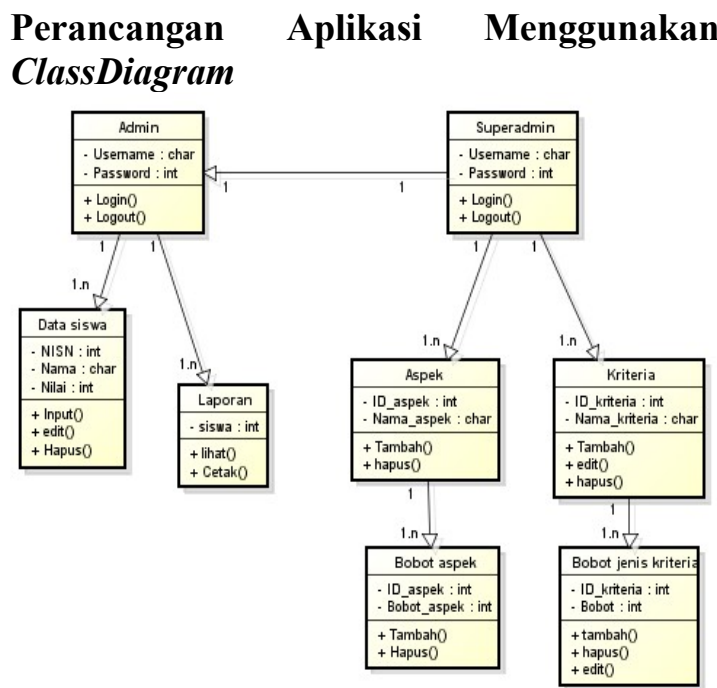

Gambar 3 Class Diagram

\section{Desain Tampilan Antar Muka}

Tampilan antar muka yang akan di rancang adalah tampilan SPK pemilihansiswa berprestasi yang didesain dengan karakteristik khusus sesuai dengankebutuhan input-output sistem. Desain tampilan antar muka yang dibuat antara lain :

\section{Form Login}

Halaman login menjelaskan tentang tahap awal dalam mengakses sistem tersebut. User diharuskan untuk login agar dapat mengelola aplikasi tersebut.

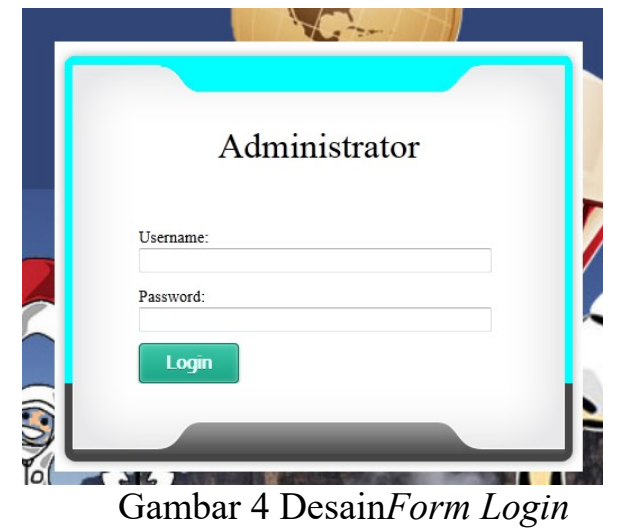

\section{2. Меnu Utama}

Menu utama merupakan halaman yang dapat diakses oleh semua user. Pada halaman utama ini dapat memilih beberapa menu yang telah disediakan.

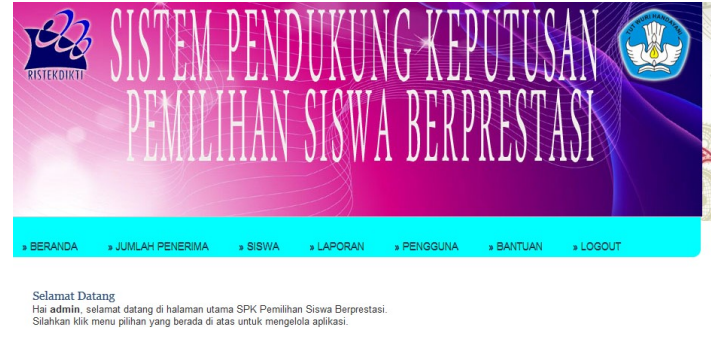

Gambar 5 Desain Menu Utama Admin

\section{Menu User}

Menu ini menjelaskan tentang data user atau pengguna aplikasi sistem pendukung keputusan ini.

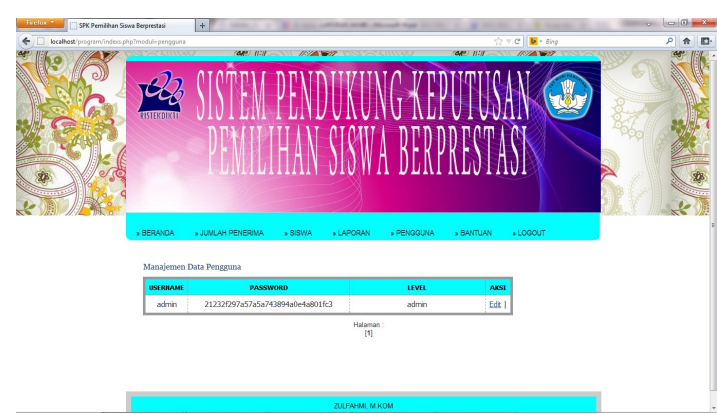

Gambar 6 Desain Menu User

4. Menu Aspek

Menu ini menjelaskan tentang aspek penilaian yang akan diedit. Menu ini hanya dapat diakses apabila user login sebagai superadmin.

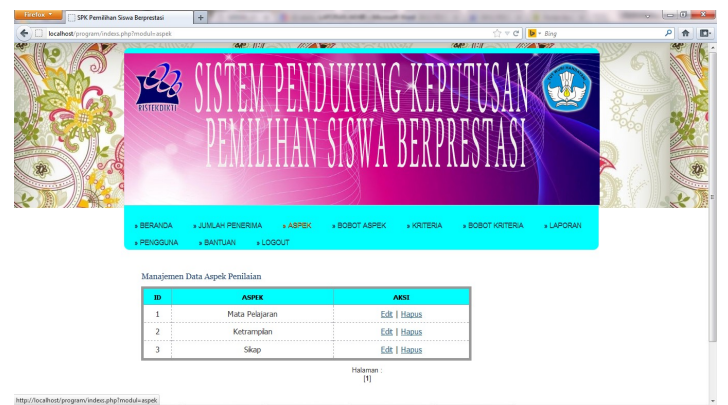

\section{Gambar 7 Desain Menu Aspek}

\section{Menu User}

Menu ini menjelaskan tentang persentase dari tiap-tiap kriteria yang akan digunakan untuk mengelola data siswa. 


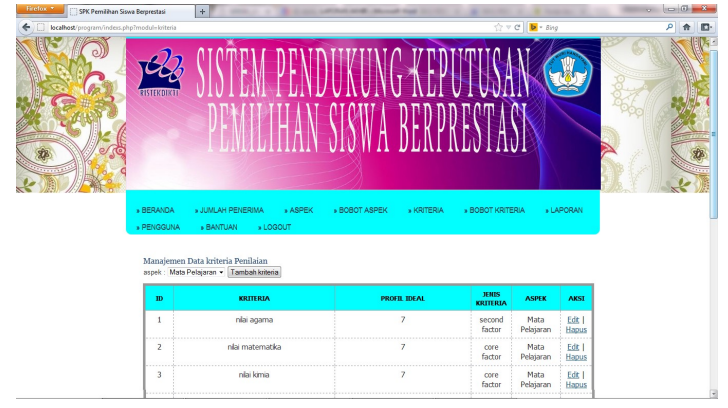

Gambar 7 Desain Menu User

\section{Menu Laporan}

Menu laporan berisi tentang laporan akhir dari data siswa yang sudah diranking dari nilai terbesar ke terkecil.

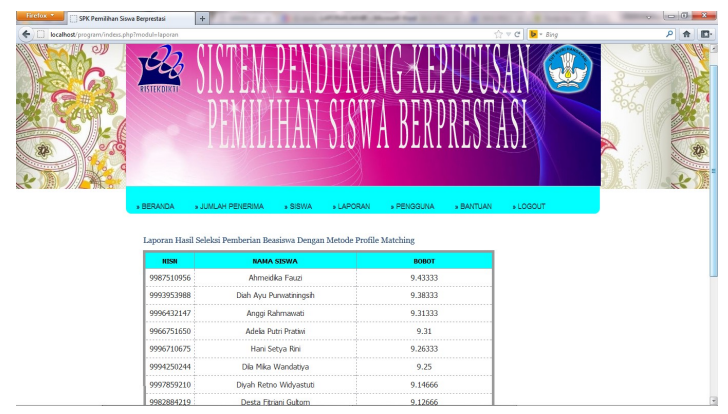

Gambar 8 Desain Menu Laporan

\section{KESIMPULAN}

Berdasarkan hasil penelitian yang dilaksanakan dapat disimpulkan bahwa sebuah aplikasi sistem pendukung keputusan dengan metode profile matching untuk pemilihan siswa berprestasi adalah salah satu metoda pengukur tingkat keberhasilan proses belajar mengajar di sekolah sehingga pihk sekolah dapat melakukan evaluasi dan memutuskan tindakan apa yang akan diambil untuk memperbaiki mutu pendidikan

\section{REFERENSI}

Alter, S. (2004). A work system view of DSS in its fourth decade. Decision
Support Systems. https://doi.org/10.1016/j.dss.2003.04. 001

Indapuri, M. (2014). SISTEM PENDUKUNG KEPUTUSAN PENERIMAAN SISWA BARU DENGAN MENGGUNAKAN METODE PROFILE MATCHING ( STUDI KASUS : MTs . ALWASLIYAH TANJUNG MORAWA ). Pelita Informatika Budi Darma, VI(2), 85-91. Retrieved from http://www.pelitainformatika.com/berkas/jurnal/18. Maulidia.pdf

Isaias, P., \& Issa, T. (2015). High level models and methodologies for information systems. High Level Models and Methodologies for Information Systems, 1-145. https://doi.org/10.1007/978-1-46149254-2

Daihani, Dadan Umar. 2001. Komputerisasi Pengambilan Keputusan. PT Elex Media Komputindo. Jakarta.

Hermawan, Julius. 2005. Membangun Decision Support System. Andi. Yogyakarta.

Imamuddin, Mohammad dan Kadri, Trihono. 2006. Penerapan Algoritma AHP Untuk Prioritas Penanganan Bencana Banjir. Seminar Nasional Aplikasi Teknologi Informasi (SNATI 2006). 17 Juni 2006, Yogyakarta, Indonesia hal. B39-B42.

Kusumadewi, Sri. 2003. Artificial Inteligence (Teknik dan Aplikasinya). Graha Ilmu. Yogyakarta.

Kusrini. 2007. Konsep Dan Aplikasi Sistem Pendukung Keputusan. Andi. Yogyakarta 